\title{
Modification Effect of Cellulase on the Physicochemical Characteristic of Polysaccharides Edible Films
}

\author{
Anna Zimoch-Korzycka, Jagoda Ambrozik-Haba, Dominika Kulig, and Andrzej Jarmoluk \\ Department of Animal Products Technology and Quality Management, Wrocław University of Environmental and Life Sciences, \\ 37 Chelmonskiego Street, 51-630 Wrocław, Poland
}

Correspondence should be addressed to Anna Zimoch-Korzycka; anna.zimoch@up.wroc.pl

Received 18 June 2015; Revised 1 August 2015; Accepted 4 August 2015

Academic Editor: Vitor Sencadas

Copyright (c) 2015 Anna Zimoch-Korzycka et al. This is an open access article distributed under the Creative Commons Attribution License, which permits unrestricted use, distribution, and reproduction in any medium, provided the original work is properly cited.

This study was conducted to assess hydrolytic influence of cellulase (C) on the physicochemical stability of chitosan $(\mathrm{CH})$ /hydroxypropyl methylcellulose (HPMC) films in time of storage $(T)$. Initially, nine films were physically characterized by contact angle, water vapour permeability (WVP), water activity $\left(a_{w}\right)$, tensile test, dynamic mechanical thermal analysis (DMTA), and thermogravimetric analysis (TGA) and chemically by Fourier Transform Infrared Spectrometry (FTIR). The contact angle results varied from $53.67^{\circ}$ to $78.33^{\circ}$. The presence of the enzyme and passing time reduced the WVP from $8.46 E-09$ to $7.41 E-09 \mathrm{~g} / \mathrm{s} \cdot \mathrm{m} \cdot \mathrm{Pa}$. The enzyme treatment improved elasticity but decreased tensile strength of films. After adding cellulase $T_{g}$ was shifted to a higher temperature. Thermal stability of the films decreased with addition of cellulase and after prolonging storage time. FTIR analysis proved that chemical changes in polysaccharides structure were caused by cellulase incorporation in films composition, which may be observed in appearance of $1656 \mathrm{~cm}^{-1}$ band. The $a_{w}$ values did not change.

\section{Introduction}

Ideal edible film or coating should have the following features: it cannot contain toxic, allergenic components; it should provide structural stability and prevent mechanical damage during transport, handling, and exposure. The edible coating should adhere well to the surface, provide complete uniform coverage of product, and control water migration to and from the protected food to maintain the desired level of water content. It has to provide semipermeability to gases, maintain the internal equilibrium of gases involved in the aerobic and anaerobic respiration, and prevent the loss or absorption of aroma and flavor and nutritional and organoleptic characteristics, which are necessary to appeal to consumer. Microbiological and biochemical stability and protection against dirt, pests, and microbial proliferation should be provided. The edible coating has to maintain or increase the aesthetic and sensory attributes of the product and act as a carrier for the desired additives (antioxidants and antimicrobials). Moreover, production process of film or coating should be simple and inexpensive [1]. The difference between the film and the coating results from the fact that the protective coatings are part of the product, while films are not necessarily integrated with the product [2].

When it comes to bioavailability, nontoxicity, biodegradability, biocompatibility, the ability to form chelates, gels, and antimicrobial and antifungal activity of chitin, chitosan and chitooligomers are excellent materials for edible films production [3, 4]. Chitosan coatings have been already characterized by the moderate water permeability and ability to oxidize lipids, reduce discoloration, maintain stability of fresh foods with a high water activity during storage at low temperatures, and minimize oil absorption during frying breaded products $[5,6]$. The mechanical properties and permeability of chitosan films can be controlled by selecting molecular weight and a suitable solvent system and adding plasticizer and dispersing or homogenizing agents [7]. Many researchers have proved better bactericidal effect of chitooligomers than chitin and chitosan $[8,9]$. Enzymatic hydrolysis of chitosan is an environmentally friendly way to obtain chitooligomers with modified properties. Enzymes are used under mild reaction conditions and are easy to control. No information is provided on physical and chemical changes of films and coatings produced with enzymes, which could 
TABLE 1: Experimental design.

\begin{tabular}{|c|c|c|c|c|c|c|}
\hline \multirow[b]{2}{*}{$\begin{array}{l}\text { Variants } \\
\text { coding }\end{array}$} & \multicolumn{2}{|c|}{ Variation factors } & \multicolumn{4}{|c|}{ Constant factors } \\
\hline & Cellulase, C [\%] & Time, $T$ [days] & Chitosan, $\mathrm{CH}$ [\%] & $\begin{array}{c}\text { Hydroxypropyl } \\
\text { methylcellulose, HPMC } \\
{[\%]}\end{array}$ & Glycerol, G [\%] & Lactic acid, LA [\%] \\
\hline C0T0 & 0 & & & & & \\
\hline C0.05T0 & 0.05 & 0 & & & & \\
\hline C0.1T0 & 0.1 & & & & & \\
\hline C0T7 & 0 & & & & & \\
\hline C0.05T7 & 0.05 & 7 & 1 & 1 & 25 & 0.25 \\
\hline C0.1T7 & 0.1 & & & & & \\
\hline $\mathrm{C} 0 \mathrm{~T} 14$ & 0 & & & & & \\
\hline C0.05T14 & 0.05 & 14 & & & & \\
\hline C0.1T14 & 0.1 & & & & & \\
\hline
\end{tabular}

provide polysaccharide hydrolysis. The exception is lysozyme incorporation to chitosan films and coatings, which was mainly used in view of its lytic action against many bacteria, compared to hydrolytic effect of polysaccharides $[10,11]$.

The aim of the study was to assess the variability of hydrolytic influence of cellulase on the polysaccharides films prepared by casting and evaluate their stability of physical and chemical properties during storage.

\section{Experimental}

2.1. Materials. Low molecular weight chitosan $(\mathrm{CH})$ from crab shells (DD $=75-85 \%)$, DL lactic acid (LA) $(85 \%$ syrup), and glycerol (G) 99\% were obtained from Sigma Aldrich, Poland. Hydroxypropyl methylcellulose (HPMC), Methocel, was purchased from Dow Chemical Co., USA. Cellulase CP CONC (C) with an activity of $120 \mathrm{U} / \mathrm{mg}$ and side activity (typical) of $30 \mathrm{U} / \mathrm{mg}$ of $\beta$-glucanase was produced by the fermentation of non-GMO Trichoderma longibrachiatum (formerly Trichoderma reesei) that was obtained from Dyadic (USA). Because of high level of cellulase and beta-1,31,4-glucanase it can break down nonstarch polysaccharides (NSP) including cellulose and beta-glucans.

2.2. Films Preparation. Cellulase stock solutions were prepared by dissolving in bidistilled water followed by centrifugation $(5000 \times \mathrm{g})$. The HPMC dissolved in bidistilled water and $\mathrm{CH}$ solubilized in $2 \%(\mathrm{v} / \mathrm{v})$ aqueous LA solutions at $1 \%$ were blended with $25 \% \mathrm{wt} / \mathrm{wt}$ of G (of dry weight of the used polymers) and $\mathrm{C}$ (at three different levels: 0\%, 0.05\%, and $0.1 \%$ ) in different ratio (wt/wt), which is shown in Table 1. All experimental samples were centrifuged at $5000 \times \mathrm{g}$ for 10 minutes to remove insoluble residues and air bubbles. Eighty $\mathrm{mL}$ of film forming solution was cast on leveled, coated with Teflon glass plate on the $80 \times 200 \mathrm{~mm}$ area, and dried at room temperature $24 \pm 0.5^{\circ} \mathrm{C}$ and $60 \% \mathrm{RH}$ for 72 hours. Films were stored after this time for 0,7 , and 14 days in the same conditions. Experimental variants were coded as follows: C0T0 refers to the film with $0 \%$ of cellulase stored 0 days and contains the rest of materials at the same level as other experimental variants, which is presented in Table 1. The films thicknesses were $0.07 \pm 0.01 \mathrm{~mm}$.

2.3. Contact Angle Measurements. Contact angles were measured in air using a Contact Angle Analyzer (Surface Electro Optics). A film sample $\left(2 \mathrm{~cm}^{2}\right)$ was put on a movable sample stage and leveled horizontally; then a drop of about $6 \mu \mathrm{L}$ of distilled water was placed on the surface of the film using a micro syringe. The contact angles were measured on both sides of the drop and averaged.

2.4. Water Vapour Permeability (WVP). Water vapour permeability of films was determined gravimetrically using ASTM E-96 method [12]. The cups were filled with $100 \mathrm{~cm}^{3}$ of distilled water each. A sample was placed in between the cup and the ring cover of each cup and stored in controlled conditions at $4^{\circ} \mathrm{C}$ and $60 \% \mathrm{RH}$. Cups were weighed every hour for $6 \mathrm{~h}$. Water vapour transmission rate (WVTP) was estimated using the following equation:

$$
\mathrm{WVTR}=\frac{G}{(t \times A)},
$$

where $G$ is the change in weight (g), $t$ is time (h), and $A$ is the test area $\left(\mathrm{m}^{2}\right)$.

WVP was calculated as

$$
\mathrm{WVP}=\frac{(\mathrm{WVPR} \times T)}{\Delta P},
$$

where $T$ is the thickness of the test specimen $(\mathrm{mm})$ and $\Delta P$ is the partial pressure difference of the water vapour across the film.

2.5. Tensile Test. Tensile test was performed in a universal Material Testing Machines Zwick/Roell Z010 following ASTM D 882.1995 method to measure the tensile strength (TS) and elongation at break (EB) [13]. The film samples were cut into $12 \mathrm{~mm} \times 65 \mathrm{~mm}$ dumbbell-shaped test specimens with contraction of the following dimensions: $7 \mathrm{~mm} \times 15 \mathrm{~mm}$. Films were stretched using a crosshead speed of $125 \mathrm{~mm} / \mathrm{min}$. 
TABLE 2: Results of contact angle, WVP, and $a_{w}$ and mechanical properties results of polysaccharides films.

\begin{tabular}{lccccc}
\hline Variants & Contact angle $\left[{ }^{\circ}\right]$ & WVP $[\mathrm{g} / \mathrm{s} \cdot \mathrm{m} \cdot \mathrm{Pa}]$ & TS $[\mathrm{MPa}]$ & EB $[\%]$ & $a_{w}$ \\
\hline C0T0 & $69.00 \pm 1.0$ & $8.46 E-09 \pm 1.3 E-09$ & $5.83 \pm 0.6$ & $6.33 \pm 0.7$ & $0.9253 \pm 0.0009$ \\
C0.05T0 & $64.00 \pm 0.6$ & $7.50 E-09 \pm 1.0 E-09$ & $5.32 \pm 0.9$ & $14.41 \pm 0.0$ & $0.9243 \pm 0.0009$ \\
C0.1T0 & $62.00 \pm 1.7$ & $8.41 E-09 \pm 1.0 E-11$ & $3.31 \pm 0.2$ & $9.87 \pm 1.5$ & $0.9250 \pm 0.0012$ \\
C0T7 & $76.00 \pm 3.1$ & $8.74 E-09 \pm 1.2 E-10$ & $3.39 \pm 0.2$ & $24.73 \pm 2.2$ & $0.9247 \pm 0.0009$ \\
C0.05T7 & $67.00 \pm 1.5$ & $9.84 E-09 \pm 3.9 E-10$ & $4.69 \pm 0.3$ & $8.11 \pm 0.1$ & $0.9253 \pm 0.0009$ \\
C0.1T7 & $62.33 \pm 1.9$ & $7.64 E-09 \pm 5.0 E-11$ & $0.92 \pm 0.2$ & $12.51 \pm 1.6$ & $0.9243 \pm 0.0009$ \\
C0T14 & $78.33 \pm 1.8$ & $7.79 E-09 \pm 2.6 E-10$ & $2.09 \pm 0.5$ & $12.52 \pm 0.2$ & $0.9250 \pm 0.0006$ \\
C0.05T14 & $53.67 \pm 1.8$ & $9.36 E-09 \pm 1.5 E-10$ & $4.77 \pm 0.6$ & $18.12 \pm 1.6$ & $0.9253 \pm 0.0009$ \\
C0.1T14 & $66.67 \pm 1.5$ & $7.41 E-09 \pm 2.0 E-10$ & $0.82 \pm 0.1$ & $24.98 \pm 2.3$ & $0.9243 \pm 0.0009$ \\
\hline
\end{tabular}

TS is defined as stress, which is measured as used force (N) per tested unit area $\left(\mathrm{mm}^{2}\right)$. EB is defined as the ratio between changed length and initial length after breakage of the test specimen.

2.6. Dynamic Mechanical Thermal Analysis (DMTA). Dynamic mechanical thermal analysis (DMTA) was performed using Rheometric Scientific DMTA Mk III. Samples were heated from $-80^{\circ} \mathrm{C}$ to $50^{\circ} \mathrm{C}$ at a heating rate of $2^{\circ} \mathrm{C} / \mathrm{min}$ and frequency of $1 \mathrm{~Hz} . E^{\prime}$, storage modulus, and $\tan \delta$, loss factor, were recorded.

2.7. Thermogravimetric Analysis (TGA). The thermal gravimetric analysis (TGA) was conducted to measure the thermal stability of chitosan films on Thermogravimetric Analyzer Hi-Res TGA 2950 (TA Instruments). The analyses were made at the temperature varying from $0^{\circ} \mathrm{C}$ to $300^{\circ} \mathrm{C}$ in an inert nitrogen atmosphere with flow of $60 \mathrm{~mL} / \mathrm{min}$ and rate warming of $10^{\circ} \mathrm{C} / \mathrm{min}$. The testing area of strips was $25 \mathrm{~mm}^{2}$.

2.8. Fourier Transform Infrared Spectrometry. Infrared spectra were registered in Infinity AR60 spectrometer (ATI Mattson). The transmission spectra were collected at $2 \mathrm{~cm}^{-1}$ resolution and by 64 scans, directly on films with a golden bridge reflexion apparatus. The reference background was air.

2.9. Water Activity. The water activity $\left(a_{w}\right)$ was measured by aw-meter (ABW Lab).

2.10. Data Analysis. All experiments were replicated three times. Average values and standard deviation were calculated using Statistica 9 (StatSoft, Poland).

\section{Results and Discussion}

The results of contact angles of polysaccharides films are shown in Table 2. The effect of time on contact angle of films is also presented in Figure 1. The contact angle values of films varied from $53.67^{\circ}$ to $78.33^{\circ}$ which was caused by simultaneous effect of cellulase dosage and storage time. When the contact angle is smaller than $90^{\circ}$, the surface is defined as hydrophilic and when it is larger than $90^{\circ}$ hydrophobic character of surface may be observed [14]. Chitosan, hydroxypropyl methylcellulose, and glycerol are hydrophilic polymers and their impact on the wettability of films surface is reflected. The HPMC and the chitosan contact angles are $75^{\circ}$ and $47^{\circ}$, respectively [15]. The $69.00^{\circ}$ contact angle was obtained for mixture of HPMC-chitosan (C0T0) in our study. The smaller the contact angle, the better the wettability and adhesiveness of chitosan [16]. The degree of samples deformation caused by contact with water can be quite large. The destruction is due to dissolution of samples by contact with water. This process is accompanied by the stress formation, which results from the sample deformation. Any chemical and physical changes taking place in the substrate surface can be confirmed by measuring the contact angle, which also allows characterizing the hydrophobicity/hydrophilicity of the surface [17]. Selected films presented in Figure 1 did not show changes in the contact angle in storage time, which demonstrates their chemical stability.

The water vapour permeability values of polysaccharides films are shown in Table 2. The highest WVP value is 9.84E$09 \mathrm{~g} / \mathrm{s} \cdot \mathrm{m} \cdot \mathrm{Pa}$ and was registered for C0.05T7. It suggests that results of WVP are affected by cellulase concentration and storage time. The presence of enzyme slightly reduced the WVP from $8.74 E-09 \mathrm{~g} / \mathrm{s} \cdot \mathrm{m} \cdot \mathrm{Pa}$ to $7.64 E-09 \mathrm{~g} / \mathrm{s} \cdot \mathrm{m} \cdot \mathrm{Pa}$ for C0T7 and C0.1T7, respectively. However, Park et al. and Duan et al. did not note any change in WVP of chitosan coatings modified by lysozyme $[18,19]$. The lowest WVP of $7.41 E-$ $09 \mathrm{~g} / \mathrm{s} \cdot \mathrm{m} \cdot \mathrm{Pa}$ was noted for C0.1T14 film, while the WVP of film with the same concentration of enzyme, not stored, was $8.41 E-09 \mathrm{~g} / \mathrm{s} \cdot \mathrm{m} \cdot \mathrm{Pa}$, which suggests the influence of time. Reduction in WVP of HPMC films with ascorbic acid, citric acid, and ginger oil was noted by Atarés et al. [20]. The highest change of WVP was observed for HPMC film with ginger oil, which indicates that permeability decreases with oil addition. Cerqueira et al. confirmed that oil and glycerol have impact on WVP of chitosan films [21]. The oil presence leads to lower WVP, while the WVP values increase when more glycerol is added. That is the reason why glycerol was used in dosage of $25 \%$ of dry weight of the used polymers in each experimental variant.

The results of tensile properties of all tested films are presented in Table 2. TS of films decreased with rising concentration of cellulase in separate periods of time. When cellulase concentration increased from 0 to $0.1 \%$, the tensile 


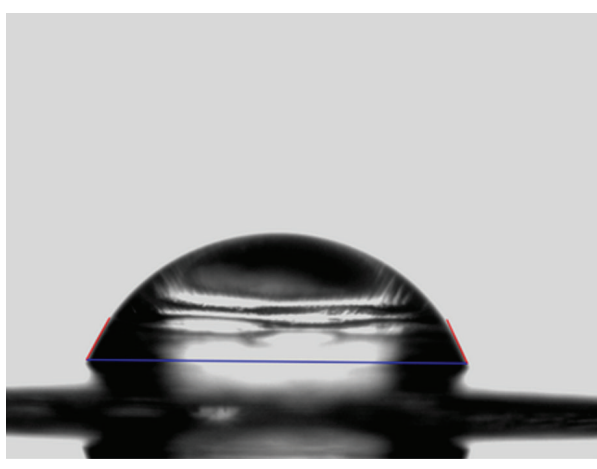

(a)

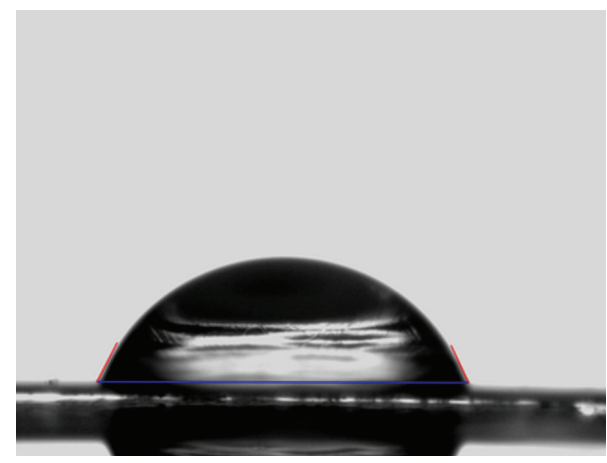

(b)

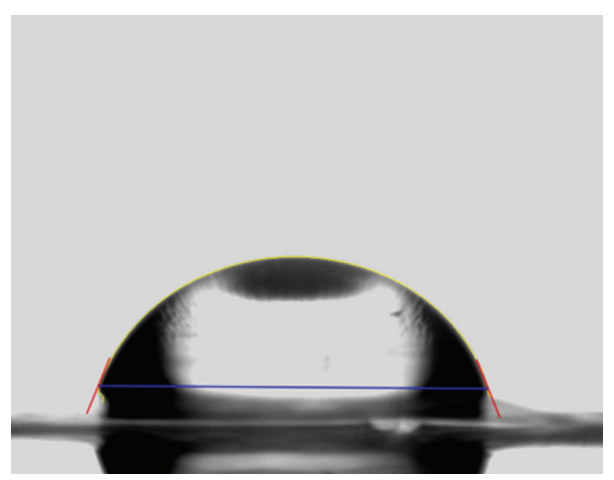

(c)

FIGURE 1: Contact angle of selected films ((a) C0.1T0; (b) C0.1T7; (c) 0.1T14).

strength decreased from 5.32 to $3.31 \mathrm{MPa}$, from 3.39 to $0.92 \mathrm{MPa}$, and from 2.09 to $0.82 \mathrm{MPa}$ after 0,7 , and 14 days of storage, respectively. Similar effect was observed in storage time, where TS value was the highest without enzyme addition. However, EB values increased linearly with increasing dosage of cellulase from 12.52 to $24.98 \mathrm{MPa}$ just in storage period of 14 days. The lowest TS of polysaccharide films was observed for C0.1T14 sample, which suggests simultaneous effect of both factors. Park et al. observed lowering TS and EB value of chitosan-lysozyme coatings with increasing enzyme addition which weakened their structure and integrity [18]. They suggest that the intermolecular hydrogen bonds of chitosan may be weakened as an effect of lysozyme addition and disrupt the formation of crystalline structure during drying. On the other hand, it could be degradation effect of cellulase on chitosan or hydroxypropyl methylcellulose chain. In view of side activities of xylanase, pectinase, mannanase, xyloglucanase, laminarase, $\beta$-glucosidase, $\beta$-xylosidase, $\alpha$ L-arabinofuranosidase, amylase, and protease in cellulase preparation, which were listed in product specification sheet, it is highly possible that hydrolysis took place. Xia et al. are of the opinion that most cellulases possess a nonspecific hydrolytic activity against chitosan, and some have even greater ability than chitosanases to degrade chitosan [22]. They also suggested that it may be related to the structural similarity of chitin, chitosan, and cellulose, which are polymers of $\mathrm{d}$-glucose linked by $\beta$-1,4-glycosidic linkages. The C-2 hydroxyl groups are replaced by amino groups in chitosan. It is possible that this enzyme does not recognize the group in C-2 position of glucose or glucosamine residue. Cellulases from Trichoderma viride and Trichoderma reesei, as well as the cellulase preparation Celluclast from $T$. reesei, were used in the degradation process of chitosan to obtain oligosaccharides by Hong and Kim [23]. They noted that the commercial Celluclast is suitable enzyme to chitooligomers production for $15 \mathrm{~h}$.

The temperature dependence of storage modulus $\left(E^{\prime}\right)$ and $\tan \delta$ for polysaccharides films with addition of the cellulase and in storage time was measured with a DMTA and results are shown in Figures 2(a) and 2(b), respectively. Storage modulus is indicated as rigidity of polymers. The glass transition is seen as a drop in the storage modulus [24]. The curves of the storage modulus versus temperature of films with enzyme showed the main relaxations, at $-20-20^{\circ} \mathrm{C}$. The storage modulus of film with the highest concentration of cellulase after 14 days of storage was almost constant during temperature degradation while samples with lower concentration and without enzyme were decreased with rising temperature. The $E^{\prime}$ curves decreased from $715 \mathrm{MPa}$ for C0T0 to $49 \mathrm{MPa}$ for C0.1T14 films. The loss factor $\tan \delta$ shows a few peaks, which are assigned to the relaxation processes $\alpha$ and $\beta$. The $\beta$ relaxation is attributed to local mode in amorphous phase and the $\alpha$ relaxation is related to the glass transition of the amorphous phase, which is controlled by intra- and intermolecular interactions [25]. When the loss tangent is in the range $0<\delta<90^{\circ}$, the material shows 


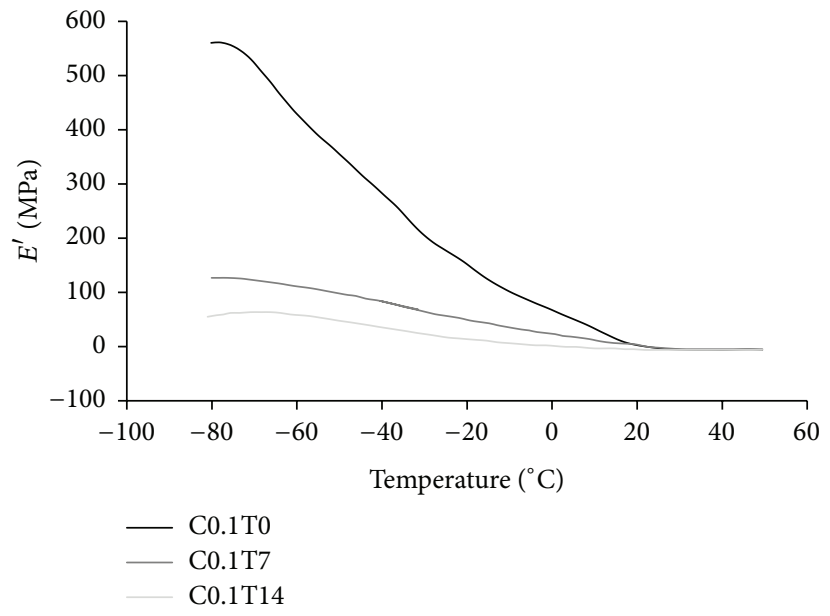

(a)

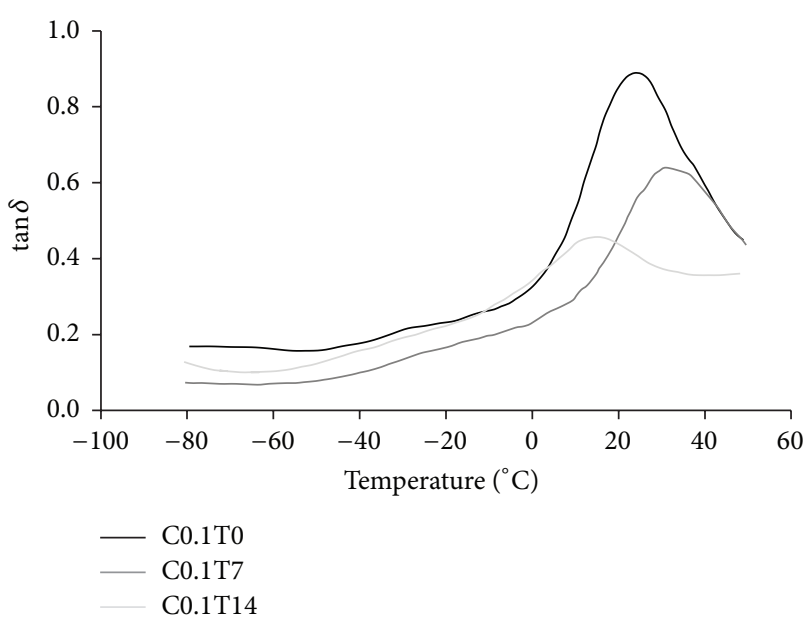

(b)

Figure 2: DMTA thermograms. (a) Effect of time on $E^{\prime}$ of $\mathrm{CH} / \mathrm{HPMC}$ films modified by cellulase; (b) effect of time on $\tan \delta$ of $\mathrm{CH} / \mathrm{HMPC}$ films modified by cellulose.

TABLE 3: Results of thermogravimetric analysis.

\begin{tabular}{|c|c|c|c|c|c|}
\hline Variants & $T_{e}^{\#}\left[{ }^{\circ} \mathrm{C}\right]$ & Weight loss [\%] & $T_{d}{ }^{*}\left[{ }^{\circ} \mathrm{C}\right]$ & Weight loss [\%] & $R_{300}{ }^{\#}[\%]$ \\
\hline C0T0 & $66.72 \pm 0.6$ & $12.94 \pm 0.2$ & $195.87 \pm 0.5$ & $24.56 \pm 0.5$ & $25.24 \pm 0.8$ \\
\hline С0.05T0 & $55.93 \pm 0.1$ & $9.58 \pm 0.6$ & $176.15 \pm 0.6$ & $30.57 \pm 0.7$ & $47.13 \pm 0.2$ \\
\hline C0.1T0 & $61.43 \pm 0.5$ & $8.63 \pm 0.9$ & $178.81 \pm 1.1$ & $30.99 \pm 0.4$ & $47.21 \pm 0.9$ \\
\hline C0T7 & $60.99 \pm 0.5$ & $14.45 \pm 0.1$ & $196.68 \pm 1.1$ & $61.46 \pm 0.3$ & $24.01 \pm 0.3$ \\
\hline C0.05T7 & $60.82 \pm 0.3$ & $7.79 \pm 0.2$ & $185.74 \pm 1.8$ & $29.17 \pm 1.2$ & $47.69 \pm 0.6$ \\
\hline C0.1T7 & $59.25 \pm 0.4$ & $7.65 \pm 0.2$ & $178.39 \pm 1.1$ & $32.10 \pm 1.0$ & $47.46 \pm 1.3$ \\
\hline $\mathrm{C} 0 \mathrm{~T} 14$ & $61.24 \pm 0.3$ & $12.37 \pm 0.5$ & $190.97 \pm 0.8$ & $62.53 \pm 0.4$ & $24.87 \pm 0.4$ \\
\hline C0.05T14 & $61.23 \pm 0.7$ & $7.20 \pm 0.3$ & $182.92 \pm 3.3$ & $29.81 \pm 0.7$ & $49.69 \pm 0.3$ \\
\hline C0.1T14 & $62.47 \pm 0.2$ & $4.23 \pm 0.2$ & $176.18 \pm 1.5$ & $32.03 \pm 0.6$ & $49.36 \pm 0.4$ \\
\hline
\end{tabular}

${ }^{\#} T_{e}$ : water evaporation temperature; $T_{d}$ : pyrolysis decomposition temperature; $R_{300}$ : residual weight at $300^{\circ} \mathrm{C}$.

viscoelastic characteristics. The loss factor values were found between 0.1 and 0.9 , which reflects viscoelastic behavior of polysaccharides films. The value of $\tan \delta$ depends on the frequency and temperature. The increase in $T_{g}$ was noted after adding cellulase (data not presented).

The characterization of degradation was performed by thermogravimetric analysis and data of thermal stability and weight loss are shown in Table 3. Small weight loss from 4.23 to $14.45 \%$ was observed in all samples at temperatures lower than $80^{\circ} \mathrm{C}$. It corresponds to evaporation of moisture and bonded water from films. Strong affinity for water of polysaccharides films was proved in contact angle analysis. Pyrolysis decomposition temperature was noted between 176.15 and $196.68^{\circ} \mathrm{C}$ and is attributed to endothermic reaction, which is due to the depolymerization and evaporation of degradation products. The least thermally stable was C0.1T14, which is related to hydrolyzing effect of cellulase on polymers. The lower thermal stability is caused by decreasing of molecular weight [26]. Despite the fact that the maximum cellulase activity used in our study is displayed at temperature of $40^{\circ} \mathrm{C}$ to $57^{\circ} \mathrm{C}$ and $\mathrm{pH}$ of 4.2 to 6.5 , we can assume that hydrolytic effect is also possible at $24^{\circ} \mathrm{C}$ and $\mathrm{pH}$ of 4.0-4.5 during structuring process. Activities of endoglucanase, b-glucosidase, and xylanase from Aspergillus niger at $23^{\circ} \mathrm{C}$ and $\mathrm{pH}=4.5$ are $3.21 \mathrm{IU} / \mathrm{mL}, 8.40 \mathrm{IU} / \mathrm{mL}$, and $1.72 \mathrm{IU} / \mathrm{mL}$, respectively [27]. Water activity needed for enzymes action in dry chitosan films is 0.93 [28]. $a_{w}$ of our films were about 0.925 (Table 2). Very slight differences of $a_{w}$ values were observed. Simultaneously, Stefanescu et al. and Pawlak and Mucha found that chitosan may improve thermal stability of cellulose [29, 30]. The C0T0 sample occurred to be the most thermally stable. The gradual degradation, which corresponds to the charring and oxidation of the thermal decomposition products of exothermic reaction, was not observed. It may happen that the endothermic and exothermic reactions take place in the same temperature, which results in endotherm overlapping by the exotherm with partial compensation [31].

FTIR spectra of the polysaccharide films without and with cellulase in time are shown in Figure 3. The spectrum is dominated by chitosan in films composition [32]. The infrared spectrum of all tested films showed broad and intense band at $3500 \mathrm{~cm}^{-1}-2800 \mathrm{~cm}^{-1}$, corresponding to the following functional groups: the stretching vibration of $-\mathrm{OH}$ 


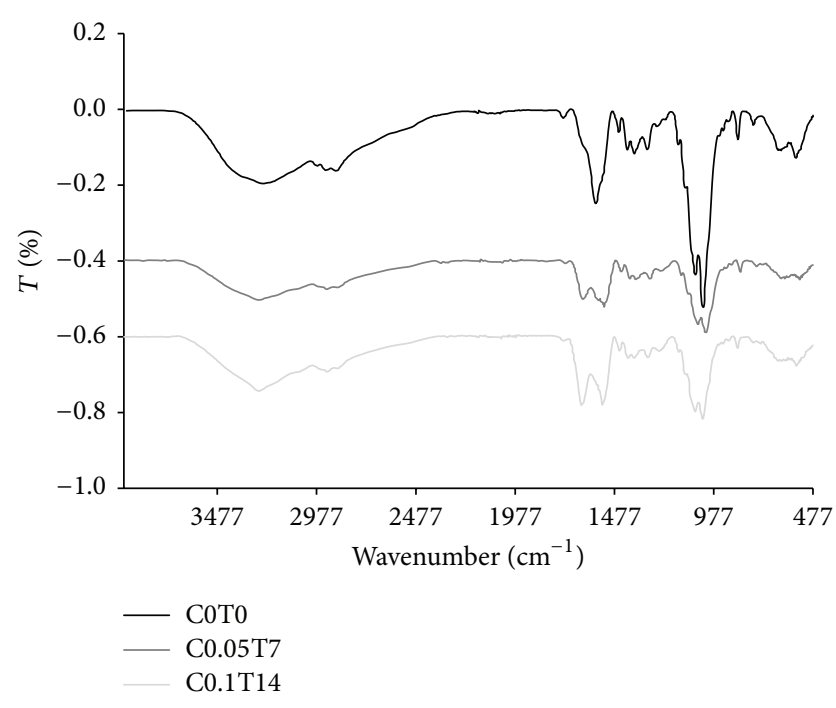

FIGURE 3: Effect of cellulase and time on FTIR spectra of CH/HPMC films.

at $3426 \mathrm{~cm}^{-1}$, the asymmetric stretching vibration of $-\mathrm{NH}_{2}$ located at a length of $3377 \mathrm{~cm}^{-1}$, the N-H stretching vibration at $3303 \mathrm{~cm}^{-1}$ indicating hydrogen molecular interaction, and the intramolecular $\mathrm{C}-\mathrm{H}$ at $2878 \mathrm{~cm}^{-1}$. The intensity of the characteristic vibration of amide bonds for GlcNHAc subunits is located at $1656 \mathrm{~cm}^{-1}, 1597 \mathrm{~cm}^{-1}$, and $1378 \mathrm{~cm}^{-1}$ and corresponds to the stretching vibration of $\mathrm{CO}$ of the secondary amide, $\mathrm{N}-\mathrm{H}$ bending of the primary amine, and symmetrical skeletal deforming $-\mathrm{CH}_{3}-$, respectively. Shin et al. noted that the intensity of the amide I and amide II bands at 1655 and $1560 \mathrm{~cm}^{-1}$ decreased because of the deacetylation of chitosan, whereas the absorption band of the newly formed amine group increases at $1590 \mathrm{~cm}^{-1}$ [33]. The peak at $1597 \mathrm{~cm}^{-1}$ for primary amine $-\mathrm{NH}_{2}$ bending disappeared or decreased when enzyme was added. At the same time, a peak of $1656 \mathrm{~cm}^{-1}$ appeared with cellulase addition. Those peaks are used as the characteristic band(s) of chitosan $\mathrm{N}$-acetylation [34]. At the same time the carboxyl group absorption band derived from lactic acid at $1730 \mathrm{~cm}^{-1}$ within COT0 spectrum disappeared in spectrum of samples with enzyme. Nah and Jang [35] also registered that peak in chitosan spectrum, but within the spectrum of low molecular, water-soluble chitosan the absorption band at $1730 \mathrm{~cm}^{-1}$ also disappeared. The wavelength of $1421 \mathrm{~cm}^{-1}$ corresponds to the bend vibration of $\mathrm{O}-\mathrm{H}$ from primary alcohol. The oligomers have shown the specific bands of the (1-4) glycosidic bridges located at $1153 \mathrm{~cm}^{-1}$ and $897 \mathrm{~cm}^{-1}$ and of the glucopyranose ring located at $1032 \mathrm{~cm}^{-1}$. Small band of low absorption in the $1733 \mathrm{~cm}^{-1}$ refers to the acylated-OH group.

\section{Conclusions}

The results of this study suggest that storage time and enzyme addition have an impact on physical and chemical properties of polysaccharides films. The use of cellulase in the edible polysaccharides films based on chitosan and HPMC did not change the water vapor permeability. The chemical stability of films in time was confirmed by contact angle results. The thermal stability studied by TGA modified by enzyme films in time was lower than CH/HPMC. All film variants showed viscoelastic behavior. According to FTIR spectroscopic analysis of chitosan/hydroxypropyl methylcellulose films, the varied physical properties are related to changes of chitosan hydrolysis. The water did not cause mechanical antiplasticization of films, because the $a_{w}$ values almost did not change for each variant. This allows for conclusion that the film properties assayed were successfully modified by incorporation of cellulase and stable during storage time.

\section{Conflict of Interests}

The authors declare that there is no conflict of interests regarding the publication of this paper.

\section{Acknowledgments}

This work was supported by Wroclaw Centre of Biotechnology, programme The Leading National Research Centre (KNOW) for years 2014-2018. The authors would like to thank Marcin Zaród and Bartosz Głębocki from The Centre of Molecular and Macromolecular Studies, Polish Academy of Sciences in Lodz.

\section{References}

[1] A. E. Pavlath and W. Orts, "Edible films and coatings: why, what, and how?" in Edible Films and Coatings for Food Applications, M. E. Embuscado and K. C. Huber, Eds., pp. 1-23, Springer, New York, NY, USA, 2009.

[2] A. Gennadios, Protein-Based Films and Coatings, CRC Press, Boca Raton, Fla, USA, 2002.

[3] C. Rosca, M. I. Popa, G. Lisa, and G. C. Chitanu, "Interaction of chitosan with natural or synthetic anionic polyelectrolytes. 1 . The chitosan-carboxymethylcellulose complex," Carbohydrate Polymers, vol. 62, no. 1, pp. 35-41, 2005.

[4] P. K. Dutta, S. Tripathi, G. K. Mehrotra, and J. Dutta, "Perspectives for chitosan based antimicrobial films in food applications," Food Chemistry, vol. 114, no. 4, pp. 1173-1182, 2009.

[5] S. Guilbert, N. Gontard, and L. G. M. Gorris, "Prolongation of the shelf-life of perishable food products using biodegradable films and coatings," LWT_Food Science and Technology, vol. 29, no. 1-2, pp. 10-17, 1996.

[6] S. Guilbert, "Edible films and coatings and biodegradable packaging," Bulletin of the IDF, vol. 346, pp. 10-16, 2000.

[7] A. P. Martínez-Camacho, M. O. Cortez-Rocha, J. M. EzquerraBrauer et al., "Chitosan composite films: thermal, structural, mechanical and antifungal properties," Carbohydrate Polymers, vol. 82, no. 2, pp. 305-315, 2010.

[8] M. S. Benhabiles, R. Salah, H. Lounici, N. Drouiche, M. F. A. Goosen, and N. Mameri, "Antibacterial activity of chitin, chitosan and its oligomers prepared from shrimp shell waste," Food Hydrocolloids, vol. 29, no. 1, pp. 48-56, 2012.

[9] A. Zimoch-Korzycka, C. Gardrat, A. Castellan, A. Jarmoluk, and V. Coma, "The use of lysozyme to prepare biologically active chito-oligomers," Polímeros, vol. 25, no. 1, pp. 35-41, 2015. 
[10] M. Yuceer and C. Caner, "Antimicrobial lysozyme-chitosan coatings affect functional properties and shelf life of chicken eggs during storage," Journal of the Science of Food and Agriculture, vol. 94, no. 1, pp. 153-162, 2014.

[11] A. Zimoch-Korzycka and A. Jarmoluk, "The use of chitosan, lysozyme, and the nano-silver as antimicrobial ingredients of edible protective hydrosols applied into the surface of meat," Journal of Food Science and Technology, 2014.

[12] ASTM, "Standard test methods for water vapor transmission of materials," ASTM E96/E96M-13, ASTM International, West Conshohocken, Pa, USA, 2013.

[13] ASTM International, ASTM D882-12 Standard Test Method for Tensile Properties of Thin Plastic Sheeting, ASTM International, West Conshohocken, Pa, USA, 2012.

[14] Y. Yuan and T. R. Lee, "Contact angle and wetting properties," in Surface Science Techniques, G. Bracco and B. Holst, Eds., vol. 51 of Springer Series in Surface Sciences, pp. 3-34, Springer, Berlin, Germany, 2013.

[15] A. Alhalaweh, A. Vilinska, E. Gavini, G. Rassu, and S. P. Velaga, "Surface thermodynamics of mucoadhesive dry powder formulation of zolmitriptan," AAPS PharmSciTech, vol. 12, no. 4, pp. 1186-1192, 2011.

[16] N. Mati-Baouche, P.-H. Elchinger, H. de Baynast, G. Pierre, C. Delattre, and P. Michaud, "Chitosan as an adhesive," European Polymer Journal, vol. 60, pp. 198-213, 2014.

[17] Y. Y. Durmaz, M. Sangermano, and Y. Yagci, "Surface modification of UV-cured epoxy resins by click chemistry," Journal of Polymer Science Part A: Polymer Chemistry, vol. 48, no. 13, pp. 2862-2868, 2010.

[18] S.-I. Park, M. A. Daeschel, and Y. Zhao, "Functional properties of antimicrobial lysozyme-chitosan composite films," Journal of Food Science, vol. 69, no. 8, pp. M215-M221, 2004.

[19] J. Duan, K. Kim, M. A. Daeschel, and Y. Zhao, "Storability of antimicrobial chitosan-lysozyme composite coating and filmforming solutions," Journal of Food Science, vol. 73, no. 6, pp. 321-329, 2008.

[20] L. Atarés, R. Pérez-Masiá, and A. Chiralt, "The role of some antioxidants in the HPMC film properties and lipid protection in coated toasted almonds," Journal of Food Engineering, vol. 104, no. 4, pp. 649-656, 2011.

[21] M. A. Cerqueira, B. W. S. Souza, J. A. Teixeira, and A. A. Vicente, "Effect of glycerol and corn oil on physicochemical properties of polysaccharide films-a comparative study," Food Hydrocolloids, vol. 27, no. 1, pp. 175-184, 2012.

[22] W. Xia, P. Liu, and J. Liu, "Advance in chitosan hydrolysis by non-specific cellulases," Bioresource Technology, vol. 99, no. 15, pp. 6751-6762, 2008.

[23] S. P. Hong and D. S. Kim, "Clone and characteristics of cellulases from Trichodermaviride and Trichodermareesei," Korean Journal of Food Science and Technology, vol. 30, pp. 245-252, 1998.

[24] A. H. Doulabi, H. Mirzadeh, and M. Imani, "Interaction and miscibility study of fumarate-based macromers with chitosan," Materials Chemistry and Physics, vol. 139, no. 2-3, pp. 515-524, 2013.

[25] M. Mucha and A. Pawlak, "Thermal analysis of chitosan and its blends," Thermochimica Acta, vol. 427, no. 1-2, pp. 69-76, 2005.

[26] S. R. Tatro, G. R. Baker, K. Bisht, and J. P. Harmon, "A MALDI, TGA, TG/MS, and DEA study of the irradiation effects on PMMA," Polymer, vol. 44, no. 1, pp. 167-176, 2003.

[27] C. S. Farinas, M. M. Loyo, A. Baraldo, P. W. Tardioli, V. B. Neto, and S. Couri, "Finding stable cellulase and xylanase: evaluation of the synergistic effect of $\mathrm{pH}$ and temperature," New Biotechnology, vol. 27, no. 6, pp. 810-815, 2010.

[28] N. Gontard, R. Thibault, B. Cuq, and S. Guilbert, "Influence of relative humidity and film composition on oxygen and carbon dioxide permeabilities of edible films," Journal of Agricultural and Food Chemistry, vol. 44, no. 4, pp. 1064-1069, 1996.

[29] C. Stefanescu, W. H. Daly, and I. I. Negulescu, "Biocomposite films prepared from ionic liquid solutions of chitosan and cellulose," Carbohydrate Polymers, vol. 87, no. 1, pp. 435-443, 2012.

[30] A. Pawlak and M. Mucha, "Thermogravimetric and FTIR studies of chitosan blends," Thermochimica Acta, vol. 396, no. 1-2, pp. 153-166, 2003.

[31] C. Qin, B. Zhou, L. Zeng et al., “The physicochemical properties and antitumor activity of cellulase-treated chitosan," Food Chemistry, vol. 84, no. 1, pp. 107-115, 2004.

[32] P. Gomes, C. A. R. Gomes, M. K. S. Batista, L. F. Pinto, and P. A. P. Silva, "Synthesis, structural characterization and properties of water-soluble $N$-( $\gamma$-propanoyl-amino acid)-chitosans," Carbohydrate Polymers, vol. 71, no. 1, pp. 54-65, 2008.

[33] Y. Shin, D. I. Yoo, and J. Jang, "Molecular weight effect on antimicrobial activity of chitosan treated cotton fabrics," Journal of Applied Polymer Science, vol. 80, no. 13, pp. 2495-2501, 2001.

[34] J. Kumirska, M. Czerwicka, Z. Kaczyński et al., "Application of spectroscopic methods for structural analysis of chitin and chitosan," Marine Drugs, vol. 8, no. 5, pp. 1567-1636, 2010.

[35] J.-W. Nah and M.-K. Jang, "Spectroscopic characterization and preparation of low molecular, water-soluble chitosan with freeamine group by novel method," Journal of Polymer Science Part A: Polymer Chemistry, vol. 40, no. 21, pp. 3796-3803, 2002. 

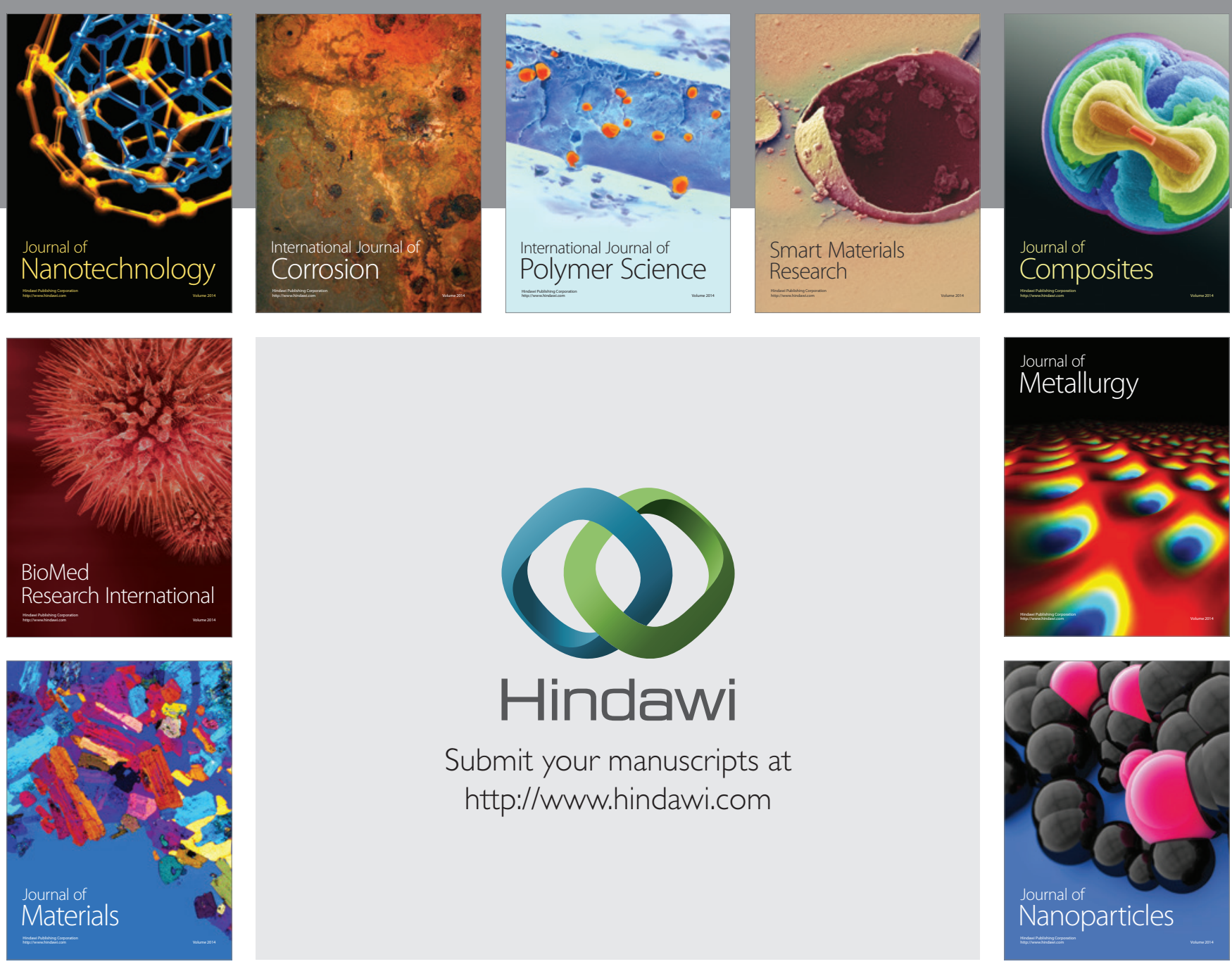

Submit your manuscripts at http://www.hindawi.com
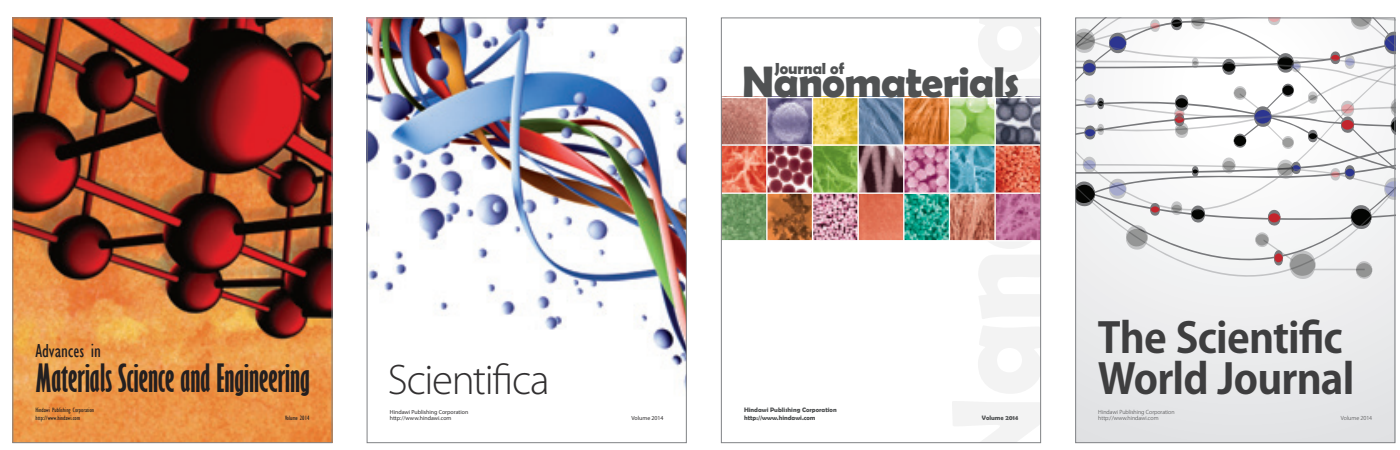

\section{The Scientific World Journal}
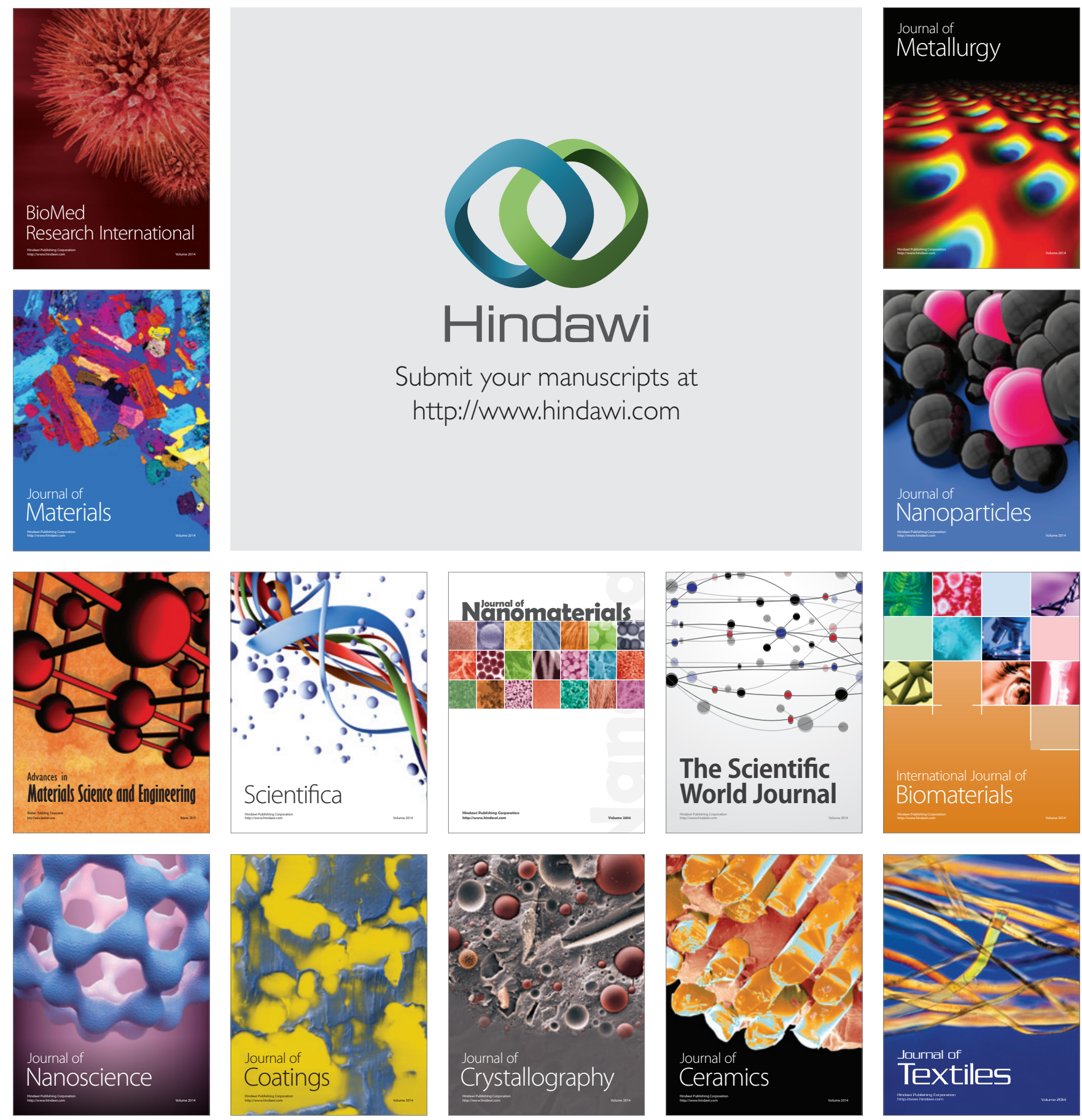